\title{
Power Quality Analysis and Evaluation at Water Pumping Station Supplied by Medium Voltage
}

\author{
${ }^{* 1}$ Mustafa SEKKELI, ${ }^{2}$ Süleyman EROL \\ ${ }^{1}$ Sutcu Imam University, Faculty of Engineering, Electrical and Electronics Depart., K. Maras, Turkey \\ ${ }^{2}$ Directorate general of GASKI, GAZİANTEP,Turkey.
}

\begin{abstract}
Power Quality (PQ) related issues are of the most concern nowadays. The widespread use of electronic equipment, such as information technology, power electronics applications, programmable logic controllers (PLC) led to a complete change of electric loads nature. These loads are simultaneously the major causers of power quality problems. Due to their non-linearity, all these loads cause disturbances in the voltage waveform. This paper deals with the measurement, analysis and evaluation of the power quality parameters in a water pumping station with a medium-voltage level. Power quality parameters such as voltage, current, active power and harmonics are measured, analyzed and evaluated taking into consideration IEEE 519-1992 standards.
\end{abstract}

Keywords: Power Quality, Harmonic, Medium Voltage 10.5505/apjes.2014.83007

\section{Introduction}

Power quality (PQ) has received a great deal of attention recently, since the increased use of power electronic devices such as converters in adjustable speed drives etc. Such devices are non-linear loads which draw nonlinear currents from the power supply. This causes distortion in the voltage and current wave form at the network [1-3]. Although there are many parameters affecting on power quality, harmonics are one of the major power quality problems in power systems. These harmonics result in some problems such as malfunctions in sensitive equipment, increased heating in the conductors and motors [4-10]. Harmonics can be described as the sum of several high-frequency sinusoidal signal components.

Given the importance of power quality, harmonics analysis and evaluation have been much more studied by researchers recently [11-13]. There are power quality standards that define the maximum allowable limit of distortion in voltage and current waveforms of the power supply. Many standards, guidelines and recommendations including IEEE standard 519-1992 and IEC 61000 series of standards have come into effect in this regard [1, 14]. Also, some indices like Total Harmonic Distortion (THD) and Total Demand Distortion (TDD), used respectively for voltage and current harmonics [1, $8]$.

In this study, an investigation is carried out to measure and evaluate the power quality in a pump station supplied by medium voltage level. This paper is organized as follows. Section 2 describes the basic knowledge of harmonic and formulations; Section 3 presents brief technical properties of installed power plant; Section 4 establishes an evaluation power quality data; finally, conclusions of overall study are presented in Section 5.

\section{Basic Knowledge of the Harmonic and Indices}

Power systems are designed to supply and operate with pure sinusoidal voltage and current waveforms. In reality, small deviations from ideal supply conditions are generally experienced. The actual waveform is composed of a number of sine waves of different frequencies, including one at the power frequency, referred to as the fundamental component and harmonics. The term "harmonic", refers to any one of the above mentioned sinusoidal components. The frequency of these components is a multiple of that of fundamental one. The amplitude of a harmonic is generally a few percent of that of the fundamental [1-4]. Fig.1 shows a typical real, fundamental and harmonic current waveform in power systems.

Harmonic indices have been developed to assess the service quality of a power system with respect to the harmonic distortion levels. These indices are measures of the effective value of a waveform and can be applied to both the current and the voltage [5-7]. The IEEE-519 document has set limits on the level of allowable harmonics [14]. Several indices are available for harmonic analysis; however, the two most commonly used are the total harmonic distortion (THD) and the total demand distortion (TDD). 


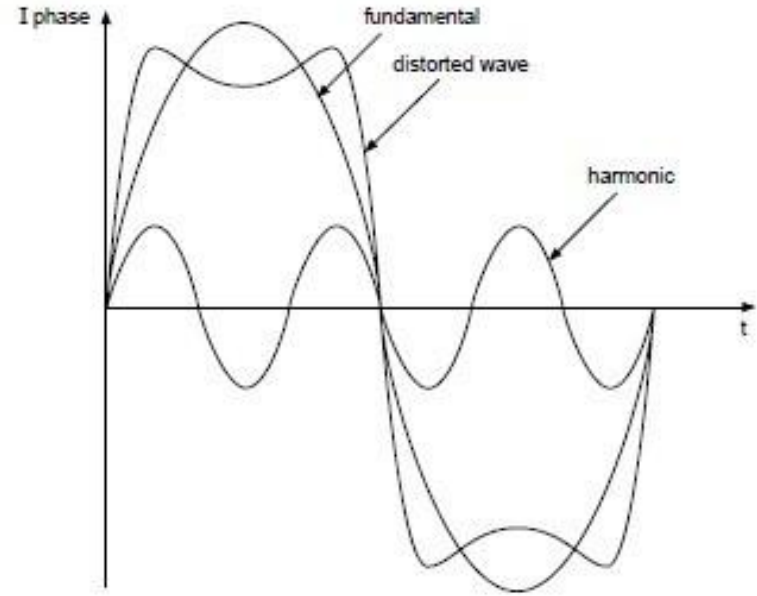

Figure 1.Typical distorted current waveform in electric power systems.

Mathematical formulations of (THD) and (TDD) for voltage and current are given in equations (1), (2) and (3) respectively $[1,4,14]$ :

$$
\begin{aligned}
& T H D_{V}=\frac{\sqrt{\sum_{h=2}^{\infty} V_{h}^{2}}}{V_{1}} \\
& T H D_{I}=\frac{\sqrt{\sum_{h=2}^{\infty} I_{h}^{2}}}{I_{1}}
\end{aligned}
$$

Where $V_{1}$ and $I_{1}$ are the RMS value of the fundamental, and $V_{h}$ and $I_{h}$ are the RMS value of the $h$ order harmonic component. Total Demand Distortion (TDD): Is the total harmonic current distortion defined by the ratio of the RMS value of the sum of the individual harmonic amplitudes to the maximum or rated demand load current $\mathrm{I}_{\mathrm{L}}$ as shown in the following expression:

$T D D_{I}=\frac{\sqrt{\sum_{h=2}^{\infty} I_{h}^{2}}}{I_{L}}$

\section{Technical Properties of Power Plant}

Drinking water is pumped to the city by means of power plant under study. There is one piece induction motor which is the rated power $\mathrm{f} 1000 \mathrm{~kW}$ in the plant. Nominal operating voltage of the motor is $10 \mathrm{kV}$. Motor is supplied by one power transformer which is rated power of $5000 \mathrm{kVA}$.
Individual system compensation is performed in the plant. Total power of capacitor connected parallel to the network is $450 \mathrm{kVAr}$. Short technical specifications of the motor, transformer and capacitor are given the Table 1 .

Table 1. Technical specifications of the motor, transformer and capacitor.

\begin{tabular}{|llc|}
\hline Transformer & Unit & \\
\hline Secondary Voltage & $(k V)$ & 10 \\
Rating & $(k V A)$ & 5000 \\
\hline Motors & & \\
\hline Operation Voltage & $(k V)$ & 10 \\
Rating & $(k W)$ & 100 \\
\hline Capacitors & & \\
\hline Voltage & $(k V)$ & 10 \\
Rating & $(k V A r)$ & 450 \\
\hline
\end{tabular}

\section{Results and Discussion}

In this study, power quality investigation has been performed in a plant supplied by medium voltage level. Voltage, current, active power and harmonics have been analyzed and evaluated based on IEEE 519-1992 standart [14]. All power quality parameters are measured and recorded while motor is loaded within nomial value and all capacitors are connected to network for full compensation.

Measurement was carried out by using AR5 type portable power analyzer. Voltage and current transformer already installed in the plant are used for this measurement. The measurement results are given and analized below in summary section. Fig. 2 shows the waveform of the three phase voltage measured from the network. As shown in Fig. 2, waveform of the voltage is not pure sinusoidal form but it has some distortions.

The single phase waveform of the voltage and current are also given in the Fig. 3. Maximum and minimum of the fundamental voltage rms value has been changed between $8500-8400$ volt while current varies between 76620-75420 milliampere.

Fig. 4 and 5 Shows the waveform of the voltage and current during motor start up respectively. As can be seen from the figure, sudden change in voltage and current is observed during starting up the motor. It is called transient one and disappears after a short period of time. Motors should be started up with the help of soft tart techniques in order to avoid any damage on the motor. 


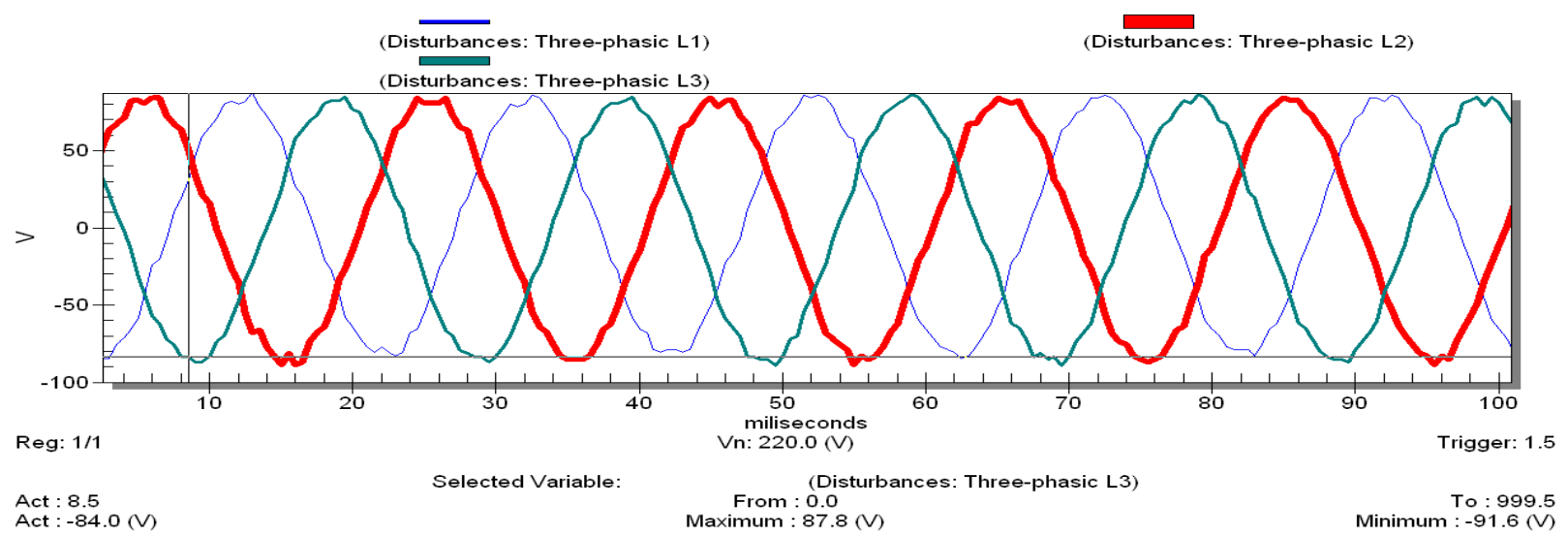

Figure 2. Voltage variations of three phases at grid.

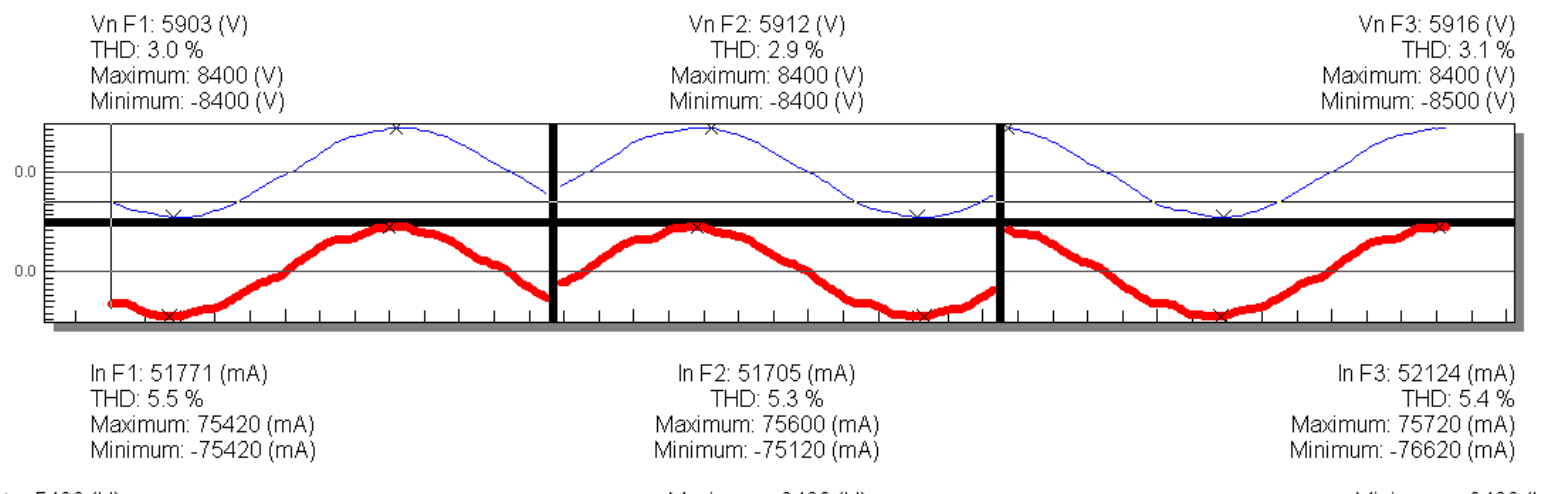

Act : $-5400(\mathrm{~V})$

Maximum : $8400(\mathrm{~V})$

Minimum : $-8400(\mathrm{~V})$

Figure 3. Single phase waveform of the voltage and current.

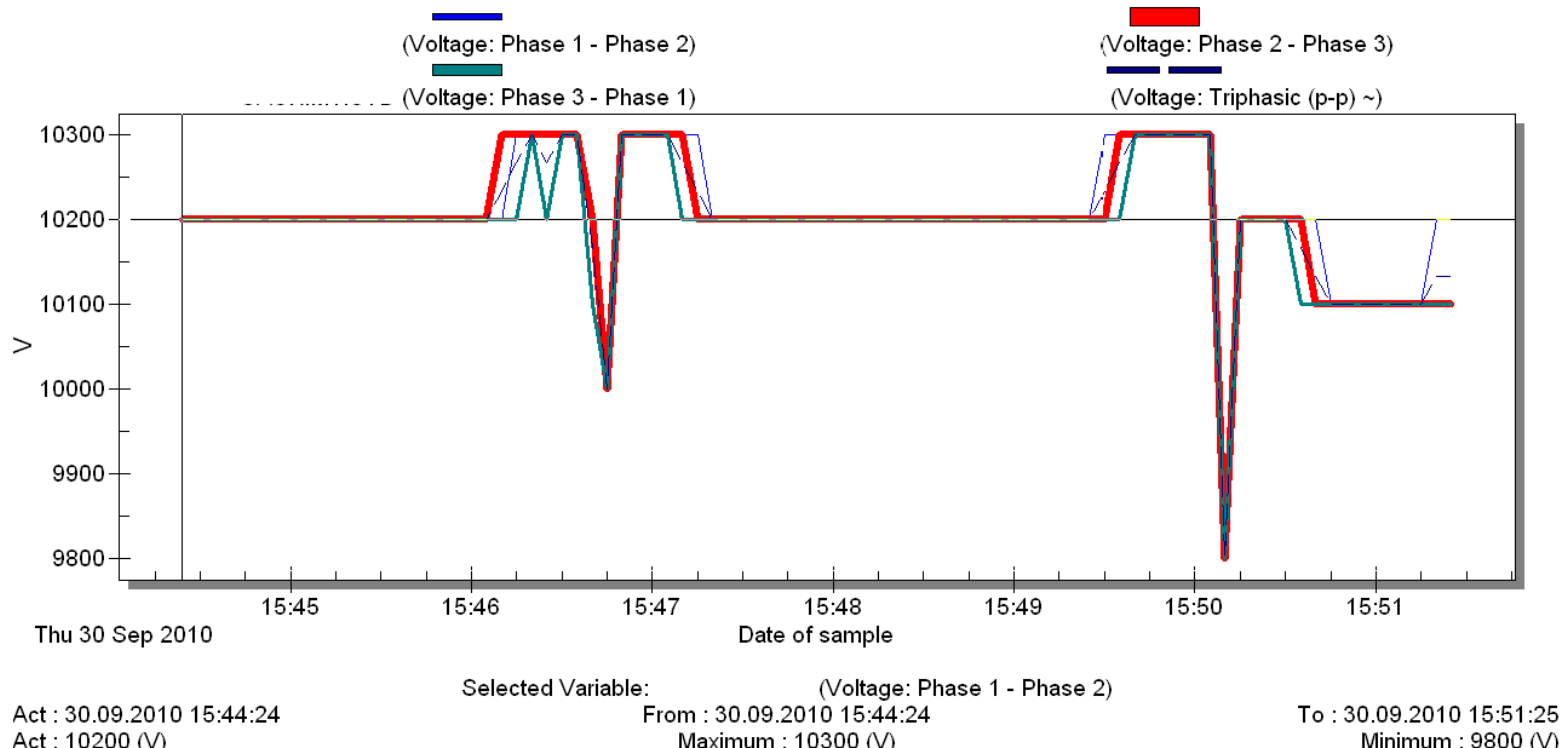

Figure 4. Voltage change of the motor during start up. 


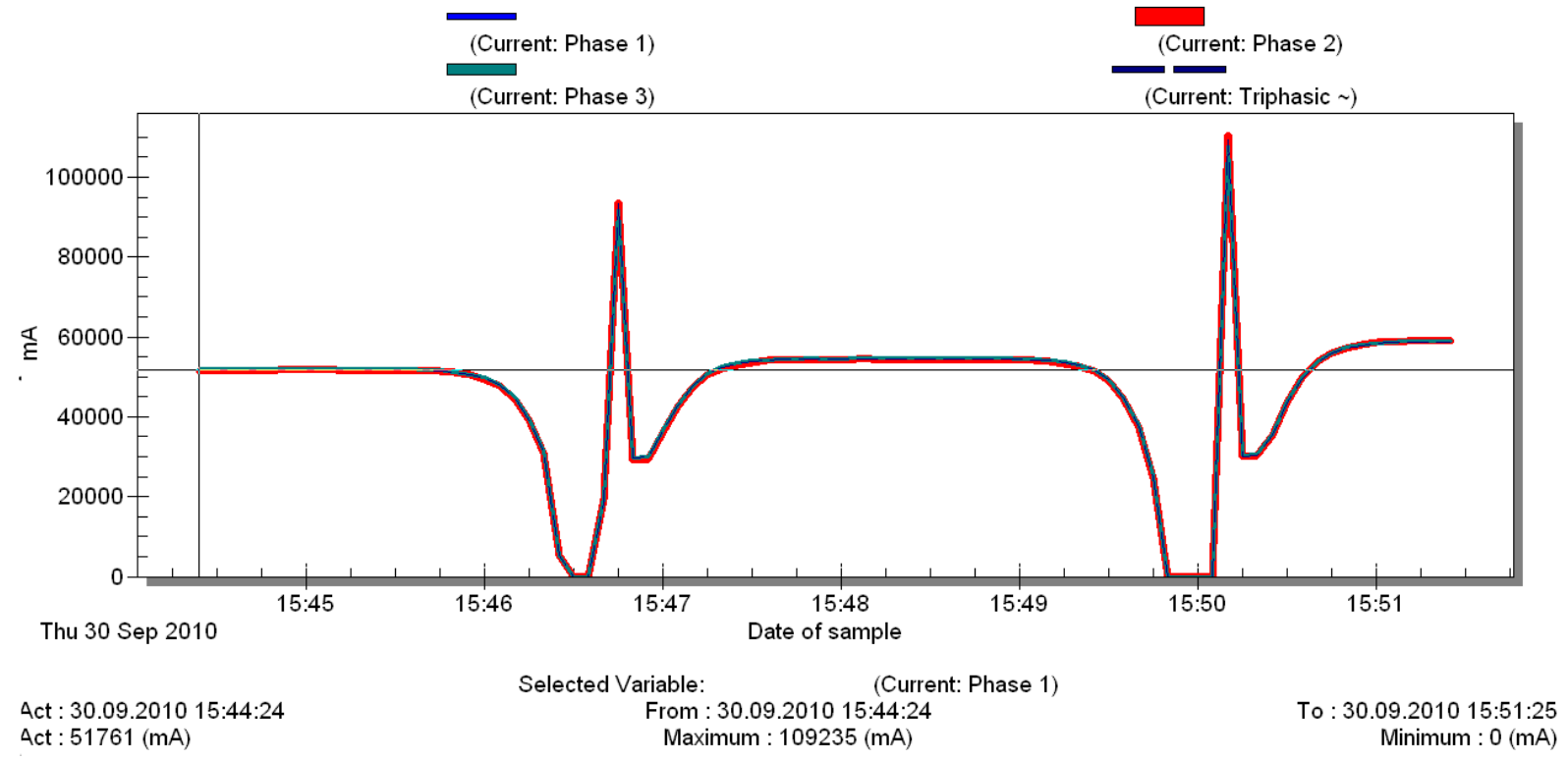

Figure 5. Current change of the motor during start up.

Additionally, waveform of the active power measured from the motor is given in Fig. 6

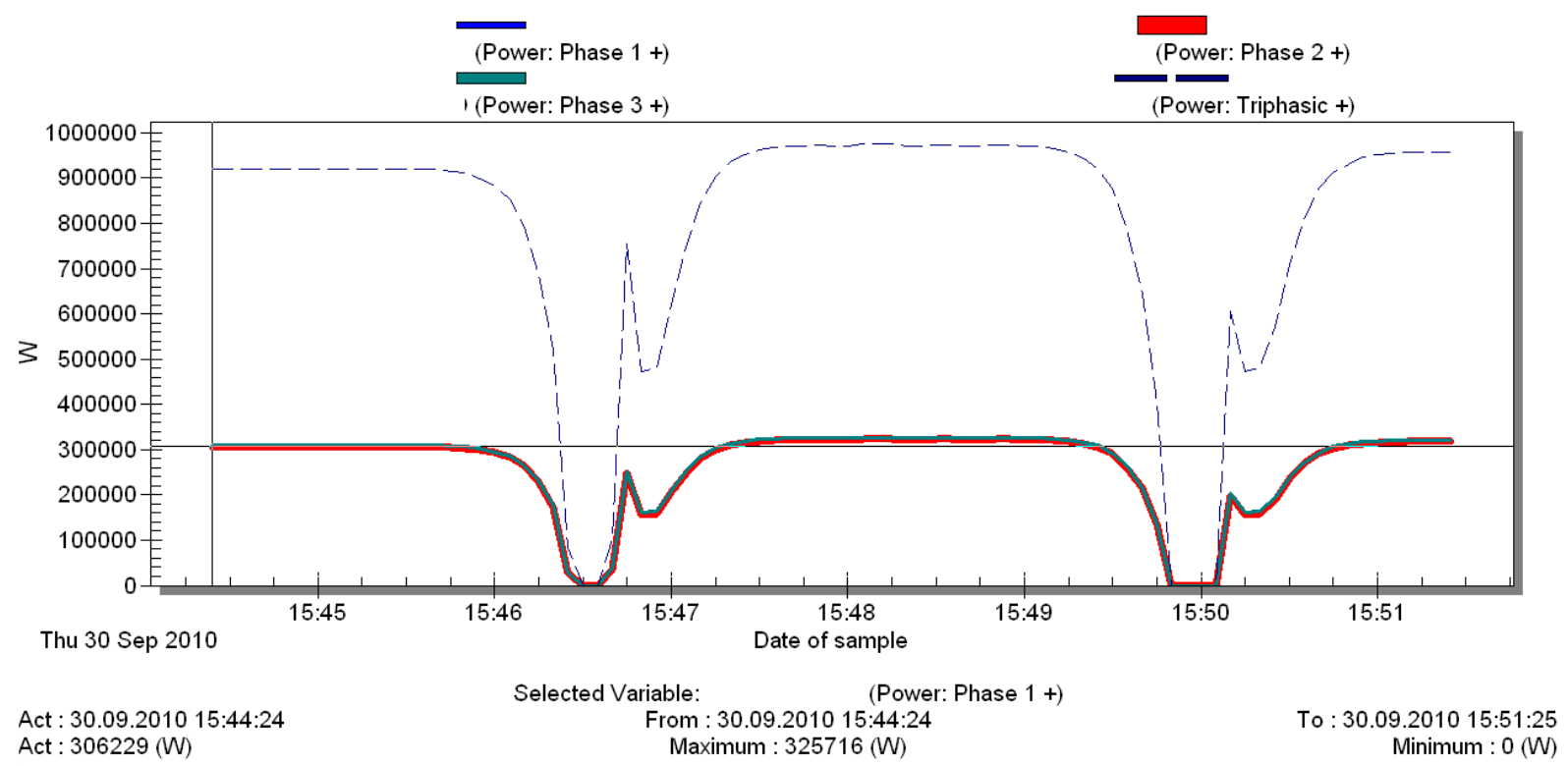

Figure 6. Avtive power change of the motor during start up

Total harmonic distortion (THD) value of the voltage and current obtained from the network buses are shown in the fig. 2. It can be seen that the fig. 2 , maximum value of the voltage THD is $3.1 \%$ at bus while the maximum value of the current THD is $5.5 \%$ at bus. Table 2 and 3 shows the total distortion limits (THD) of voltage and current according to IEEE Std. 519-1992 respectively [14].

Considering the voltage and current THD, current value is high compared with the allowed standart values while voltage value is acceptable limit. The- se values should be lowered using a proper filtering system. Fig. 7 shows the individual harmonic spectrum of voltage and current measured from power plant. There are $5^{\text {th }}$ and $7^{\text {th }}$ harmonics order for voltage spectrum while current harmonics have $5^{\text {th }}$ , $7^{\text {th }}$ and $13^{\text {th }}$. According to IEEE std. 519-1992, voltage harmonics order is within the acceptable level while $7^{\text {th }}$ harmonic order exceeds the allowable limit. 


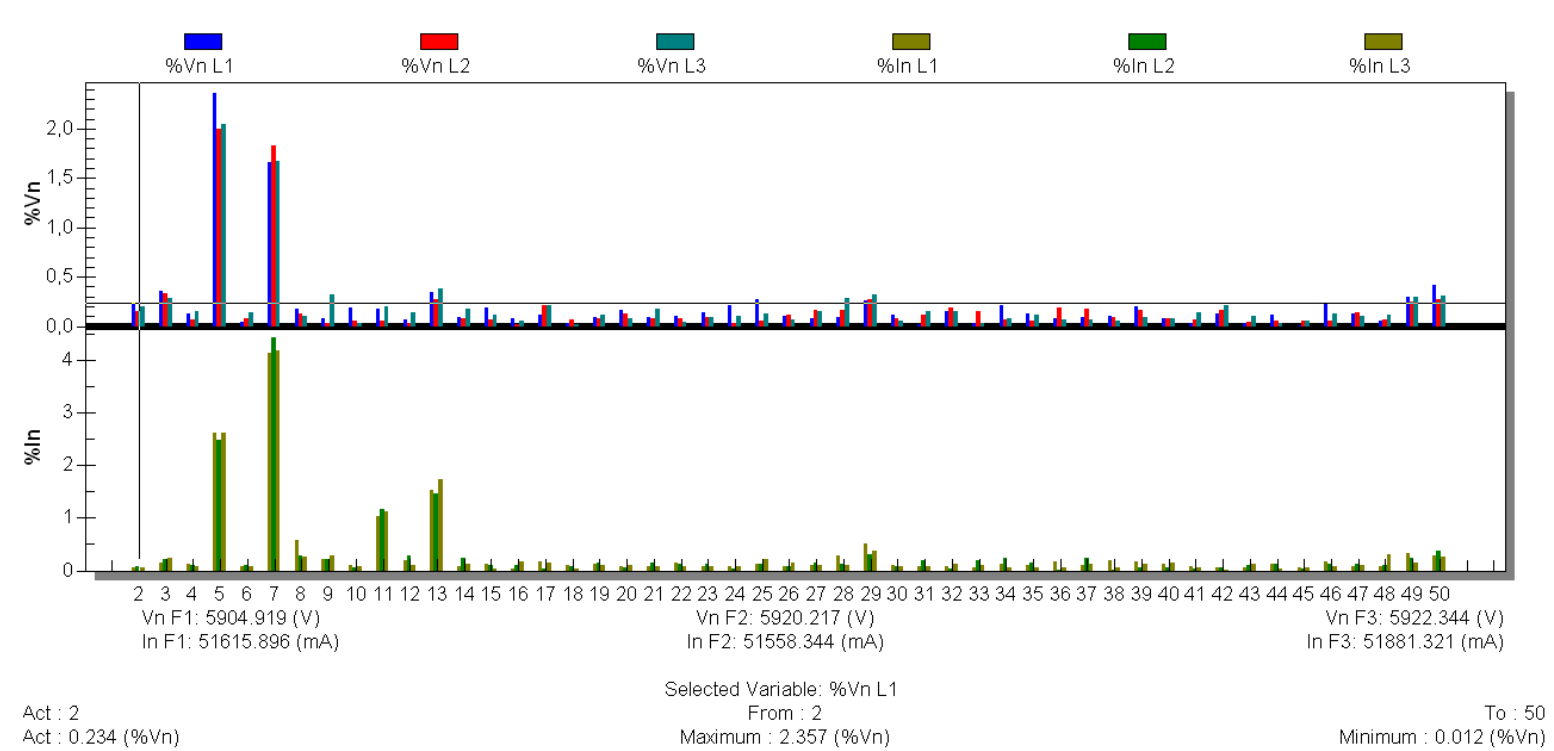

Figure 7. Indivudial harmonic spectrum of voltage and current at power plant.

Table 2. Voltage distortion limits for general distribution system.

\section{Voltage Distortion Limits}

\begin{tabular}{lll}
\hline Bus Voltage at PCC & $\begin{array}{l}\text { Individual Voltage } \\
\text { Distortion THD }(\boldsymbol{\%})\end{array}$ & $\begin{array}{l}\text { Total Voltage } \\
\text { Distortion THD (\%) }\end{array}$ \\
\hline $69 \mathrm{kV}$ and below & 3.0 & 5.0 \\
$69.001 \mathrm{kV}$ through $161 \mathrm{kV}$ & 1.5 & 2.5 \\
$161.001 \mathrm{kV}$ and above & 1.0 & 1.5 \\
\hline
\end{tabular}

Table 3. Current distortion limits for general distribution system at medium and high voltage.

\begin{tabular}{|c|c|c|c|c|c|c|}
\hline \multicolumn{7}{|c|}{$\begin{array}{l}\text { Current Distortion Limits for General Distribution Syst } \\
\text { Maximum Harmonic Current Distortion in Percent of } \mathrm{I}_{\mathrm{L}} \\
\text { Individual Harmonic Order (Odd Harmonics) }\end{array}$} \\
\hline$\overline{\mathrm{I}_{\mathrm{sc}} / \mathrm{I}_{1}}$ & $<11$ & $11<\mathrm{h}<17$ & $17<\mathrm{h}<23$ & $23<h<35$ & $35<h$ & TDD \\
\hline$<20 *$ & 4.0 & 2.0 & 1.5 & 0.6 & 0.3 & 5.0 \\
\hline $20<50$ & 7.0 & 3.5 & 2.5 & 1.0 & 0.5 & 8.0 \\
\hline $50<100$ & 10.0 & 4.5 & 4.0 & 1.5 & 0.7 & 12.0 \\
\hline $100<1000$ & 12.0 & 5.5 & 5.0 & 2.0 & 1.0 & 15.0 \\
\hline$>1000$ & 15.0 & 7.0 & 6.0 & 2.5 & 1.4 & 20.0 \\
\hline
\end{tabular}

\section{Conclusions}

In this paper, a power quality evaluation of the power plant supplied by medium voltage level under maximum loading condition is presented. Harmonics and power quality events such as voltage, current, active power have been measured, analyzed and evaluated based on IEEE 519-1992 standards. The investigations show that total harmonic distortion of current measured from the plant has slightly exceeded the limit while the voltage and other parameters are mainly good. A proper filter should be designed for harmonic elimination. After applying filters, harmonic distortions will be reduced considerably and that their maximum values are within the maximum allowable limits.

\section{Acknowledgements}

Authors would like to thank GASKI power plant, it's manager and staff of GASKI power plant for their helps, collaboration and supports in our study.

\section{References}

[1] C. Sankaran, "Power Quality", Crc press, New York, (2002).

[2] B. Ebrahim, F.K. Mohammad, "Sensitive load voltage compensation against voltage sags/swells and harmonics in the grid voltage and limit downstream fault currents using DVR", Electric Power Systems Research 83, 80-90 (2012). 
[3] M.M. Ertay, H.T. Duru, "Harmonic analysis and passive power filter design for a medium voltage power system according to IEEE standards", Energy Education Science And Technology Part A 29(2), 1253-1262 (2012).

[4] M. Sekkeli, "Investigation of Power Quality Impact on the Textile Factories", Electronic Journal of Textile Technologies 3(3), 1-11 (2009).

[5] M. Şekkeli, A.S. Yılmaz, "Bir taş kırma tesisinde güç kalitesi seviyesinin ölçümü ve değerlendirilmesi”, Pamukkale Üniversitesi Mühendislik Bilimleri Dergisi 15(3), 317-323 (2009).

[6] M. Sekkeli, N. Tarkan, "Development of a novel method for optimal use of a newly designed reactive power control relay", International Journal of Electrical Power \& Energy Systems 44, 736742 (2013).

[7] K.J. Sachin, S.N. Singh, "Harmonics estimation in emerging power system: Key issues and challenges", Electric Power Systems Research 81, 1754-1766 (2011).

[8] N. Thai, L. Yuan, "Power quality disturbance classification utilizing S-transform and binary feature matrix method", Electric Power Systems Research 79, 569-575 (2009).

[9] R. Sanae, N. Éloi, X. Jianhong, S. Pierre, "Performance evaluation of harmonics detection methods applied to harmonics compensation in presence of common power quality problems", Mathematics and Computers in Simulation 63, 363-375 (2003).
[10] Z. Ming, L. Kaicheng, H. Yisheng, "A real-time classification method of power quality disturbances", Electric Power Systems Research 81, 660-666 (2011).

[11] C. Kocatepe, A. Inan, O. Arikan, R. Yumurtaci, B. Kekezoglu, M. Baysal, A. Bozkurt, Y. Akkaya, "Power quality assessment of gridconnected wind farms considering regulations in Turkey", Renewable \& Sustainable Energy Reviews 13, 2553-2561 (2009).

[12] F.C. Victor, L.A. Patricia, "Hybrid Power Filter to Enhance Power Quality in a Medium-Voltage Distribution Network", IEEE Transactions on Industrial Electronics 5(8), 2885-2893 (2009).

[13] A.P. Stavros, S. Fritz, "Power-Quality Measurements in an Autonomous Island Grid With High Wind Penetration", IEEE Transactions on Power Delivery 21(1), 218-224 (2006).

[14] IEEE Recommended Practices and Requirements for Harmonic Control in Electrical Power Systems, IEEE Standard 519-1992, USA, (1992).

[15] M. Şekkeli, Ö. F. Keçecioğlu, H. Açıkgöz, C. Y1ld1z, "A Comparison between theoretically calculated and actually generated electrical powers of wind turbines: A case study in Belen wind farm, Turkey", Akademik Platform Mühendislik ve Fen Bilimleri Dergisi (APJES) 1(3), 41-47 (2013) 